REMOA

\title{
A ESCOLA COMO MEIO DE FORMAÇÃO PARA A APLICABILIDADE DA EDUCAÇÃO AMBIENTAL
}

\section{SCHOOL AS A MEANS OF TRAINING FOR THE APPLICABILITY OF ENVIRONMENTAL EDUCATION}

\author{
Clayton Hillig $^{1,2}$, Francieli Friedrich ${ }^{1,3}$ e Márcia Friedrich ${ }^{4,5}$ \\ Universidade Federal de Santa Maria, Av. Roraima, no 1000, Cidade Universitária, Bairro Camobi, \\ Santa Maria - RS, 97105-900 - hillig@smail.ufsm.br \\ ${ }^{2}$ Professor Adjunto do Centro de Ciências Rurais da UFSM. \\ ${ }^{3}$ Bióloga, Especialista em Educação Ambiental - EAD - UFSM \\ 4Faculdade Padrão Unidade III, Av. Anhanguera esq. c/ Rua do Algodão, Setor Rodoviário - Goiânia- \\ GO. \\ 5Professora da Faculdade Padrão e Rede Municipal de Goiânia.
}

\section{RESUMO}

Este trabalho tem como objetivo analisar a importância e o desenvolvimento das questões ambientais nas escolas. O tema Educação Ambiental foi escolhido com a intenção de analisar as ações ambientais realizadas pelos alunos, em suas residências e na escola onde estudam. A atividade foi desenvolvida em uma escola estadual da cidade de Porto Alegre/RS e contou com a atuação de três turmas do ensino fundamental. Para uma análise mais detalhada sobre suas percepções e ações envoltas ao meio ambiente, foi aplicado um questionário com cinco perguntas envolvendo suas ações na escola e em suas residências, bem como seus conhecimentos sobre o tema. Com respostas e argumentos sobre suas atitudes ecologicamente corretas, vê-se que ações que contribuem com o meio ambiente são realizadas, mas ainda sem uma totalidade ou um interesse grandiosos por determinados alunos. Com a percepção crítica aflorando, podemos ter a esperança de obter um mundo melhor pela frente.

PALAVRA-CHAVE: Educação Ambiental, aplicabilidade, escola.

\section{ABSTRACT}

This study was aimed to analyze the importance and development of environmental issues in schools. The theme of Environmental Education was chosen with the intention of analyzing the environmental initiatives undertaken by pupils in their homes and at school where they study. The activity was developed in a public school in Porto Alegre / RS and was the work of three (3) classes of elementary school. For a more detailed analysis on their perceptions and actions wrapped in the environment, a questionnaire was administered to five (5) questions involving his actions at school and in their homes, as well as their knowledge on the subject. With answers and arguments about their environmentally friendly attitudes, we see that actions that contribute to the environment are carried out, but still without a full or a grand interest for certain students. With the critical perception surfacing, we hope to get a better world ahead. 


\section{HILLIG et al, vol.(4), n4, p. 647-659, 2011. Monografias Ambientais (e-ISSN: 2236-1308)}

REMOA

KEYWORDS: Environmental Education, applicability, school.

\section{INTRODUÇÃO}

Como forma de promover a Educação Ambiental (EA) na sociedade, a inserção da mesma tornouse uma ferramenta fundamental a ser trabalhada nas escolas. A busca de atitudes que minimizem os efeitos negativos ao meio ambiente surgem como possibilidade de trabalho interdisciplinar e extraclasse, além de trabalhos curriculares. Diferentes assuntos podem ser trabalhados em sala de aula utilizando o tema EA. Assuntos esses que ainda encontram-se em condições de ser inseridos em diferentes disciplinas. Depreende-se daí que o trabalho educacional e ambiental permite que os professores atualizem constantemente, buscando idéias inovadoras e eficazes no ideal proposto.

Exercitar os alunos a pensar e agir na redução, reutilização e reciclagem do lixo, destinação do lixo hospitalar, o consumo, desperdício e poluição das águas, a preservação das florestas, os efeitos das queimadas, utilização de agrotóxicos, caça ilegal, respeito aos animais, entre outros assuntos, certamente trará resultados positivos ao meio ambiente.

Segundo Demo (2007), a pesquisa, conduz o educador á qualificação e troca de experiências, visualizando, assim, um potencial positivo no resultado final para educadores e educandos. Com a freqüente troca de idéias entre o corpo docente de uma instituição, novas propostas podem ser trabalhadas em diferentes disciplinas e, com essa interdisciplinaridade permitir um trabalho constante na EA. A questão que envolve a EA traz preocupações aos professores de ciências e áreas afins. Manter acesa em seus alunos a consciência ecológica torna-se um desafio quando essa educação não vem de suas próprias casas.

Segundo Jacobi (2003) com a preocupação voltada ao desenvolvimento sustentável e a preocupação em manter o que ainda resta de recursos naturais, mudanças sociopolíticas devem ser desenvolvidas com maior ênfase. A preocupação com a redução dos recursos naturais deve ser exposta aos cidadãos desde o início de sua formação acadêmica. Para tanto, a formação destes sujeitos cidadãos visa um fortalecimento populacional como um todo, resultando na própria qualidade de vida.

Para manter trabalhos constantes envolto a ações ecologicamente corretas, as escolas buscam em palestras e trabalhos extraclasse maneiras de expandir o assunto. Trabalhos que envolvem a EA são levados e apresentados em sala de aula, buscando um retorno sempre crescente de quem participa. Preocupados com a formação cidadã dos jovens que freqüentam as salas de aula das escolas porto alegrenses, estudantes de graduação e mestrados tentam expandir seus trabalhos ao longo das escolas estaduais. Para tanto, a busca constante de voluntários na ação ecológica cresce cada vez mais, levando biólogos e profissionais de áreas afins a lutar contra quem insiste em tomar atitudes danosas ao meio ambiente.

Igualmente, trabalhos que envolvem crianças em escolas tornam-se um recurso a ser explorado, por permitir que esses cidadãos cresçam com a visão correta do meio que os cerca, incentivando-os cada vez mais na atividade ecológica. Os alunos de ensino fundamental surgem como público fundamental para esse processo de aprendizado. Os mesmos têm a condição de expandir esse aprendizado em suas residências, levando às pessoas menos instruídas informações de importância mundial. 


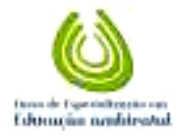

HILLIG et al, vol.(4), n4, p. 647-659, 2011.

REMOA

Monografias Ambientais (e-ISSN: 2236-1308)

Para esta pesquisa a busca de respostas para algumas questões ambientais foi em uma escola estadual na cidade de Porto Alegre/RS. O instrumento de coleta de dados foi o questionário, tendo em vista que o mesmo possibilita uma pesquisa baseada em informações fornecidas pelo próprio público alvo. O questionário foi aplicado em três turmas do ensino fundamental (6으, 70 e 8 o anos), totalizando 75 alunos. Diante do exposto objetiva-se com esta pesquisa, saber quais as atividades voltadas a Educação Ambiental desenvolvidas na área escolar e residencial que envolve o público alvo.

Paralelamente aos objetivos serão analisadas situações referentes à situação ambiental mundial. Verificar com os alunos quais seus conhecimentos referentes à Educação Ambiental? Quais suas ações frente a ameaças ambientais? E, principalmente, se há incentivo para com os mesmos no ambiente escolar e residencial. Intenciona-se, igualmente avaliar as ações ecológicas realizadas pelos alunos, incentivando-os a buscar correções quando deparados com atitudes danosas ao meio ambiente identificando e agindo frente a situações ecológicas incorretas.

Para um trabalho eficaz sobre o assunto é necessário uma rede de atuação nas escolas, partindo não só dos gestores como também de toda a comunidade escolar, proporcionando assim, uma transposição dos muros escolares.

\section{MÉTODO}

Realizar uma pesquisa é segundo Ludke e André (1986) "promover um confronto entre os dados, as evidências, as informações coletadas sobre um determinado assunto", para mais tarde dialogar com os referenciais teóricos na produção do conhecimento.

Esta é uma pesquisa básica do ponto de vista da sua natureza, pois objetiva "gerar conhecimentos novos úteis para o avanço da ciência" [...] "envolve verdades e interesses universais" (FERNANDES,

2010, p. 32).

Classifica-se como quanti - qualitativa e descritiva segundo a abordagem do problema visando dessa forma à interpretação dos fenômenos e atribuição de significados, sendo o processo e significação focos principais. Na busca da consecução de seus objetivos a mesma se classifica como exploratória com levantamento de dados, pois é a pesquisa que busca informação diretamente com o grupo de interesse a respeito dos objetivos.

A coleta de dados para o desenvolvimento desta envolveu visita ao local escolhido e intervenção no ambiente por meio de palestras logo após aplicação de um questionário para contemplar objetivos deste trabalho. O espaço para o desenvolvimento desta pesquisa foi uma escola estadual em Porto Alegre/RS. Esta escola conta com turmas de ciências de 6ㅇ a 8으 anos no turno da tarde, portanto, turmas onde foram aplicados os questionários. O 9o ano não fez parte da pesquisa por ser oferecida somente no turno da manhã.

A escola que gentilmente se dispôs a acompanhar esse trabalho situa-se em uma área de classe média da cidade de Porto Alegre/RS, embora seus alunos venham dos mais diferentes bairros da cidade. A mesma solicitou um trabalho aos seus alunos que complementasse a pesquisa, para tanto, antecedendo a aplicação dos questionários os alunos assistiram uma palestra sobre o tema proposto.

O questionário respondido pelos alunos conta com cinco questões direcionadas especificamente ao tema abordado, tendo em vista o propósito desta. Dividiu-se em dois grupos: O primeiro referindo-se à caracterização do grupo pesquisado, e o segundo dividido em blocos, intencionou 


\section{HILLIG et al, vol.(4), n4, p. 647-659, 2011. Monografias Ambientais (e-ISSN: 2236-1308)}

REMOA

aspectos relacionados a atitudes ambientais em relação ao aluno (pesquisado), ao ambiente familiar, ao ambiente escolar e um bloco (pergunta) direcionado a investigar os conhecimentos dos alunos acerca das mudanças ambientais percebidas no seu contexto social. Cada aluno recebeu e respondeu as questões individualmente sendo retornados assim que conclusos pelos mesmos.

Ressaltamos a importância deste instrumento, o questionário, pois segundo Friedrich $(2009$, p. 50) o mesmo "se constituiu pela utilização da linguagem escrita". Ao responder o questionário, o pesquisado precisa, "usar a linguagem escrita e, esta, precisa transferir a linguagem interior para o exterior" (VYGOTSKY, 2000 apud BENITE e BENITE, 2008, p. 13).

Devemos ainda ressaltar que a linguagem escrita é carregada de intencionalidade, e que é a consciência e a interação que orientam a escrita. Seu emprego, portanto, exige uma ação mais abstrata e intelectualizada (FRIEDRICH, 2009).

Segundo Marconi e Lakatos (2003), o questionário constitui uma série ordenada de perguntas, que devem ser respondidas por escrito sem a presença do entrevistador. É um instrumento que apresenta algumas vantagens dentre as quais podemos citar: economia de tempo, pois atinge um grande número de pessoas simultaneamente, abrange uma área geográfica mais ampla, economia de pessoal, obtém respostas mais rápidas e mais precisas, proporciona maior liberdade nas respostas, em razão do anonimato e por isso, há mais segurança, menos risco de distorção pela não intervenção do pesquisador e obtêm-se respostas que materialmente seriam inacessíveis.

O tema apresentado foi satisfatório ao grupo de professores da escola, pois os mesmos preocupam- se com a atuação de seus alunos em relação à educação ambiental, disponibilizou as turmas de ciências do turno vespertino.

\section{DISCUSSÃO DOS RESULTADOS}

De posse dos dados passamos a analisar e discutir os mesmos no intuito de promover a produção de conhecimento gerada.

Inicialmente analisaremos o perfil do público alvo. Esta caracterização torna-se importante para situar ontologicamente os entrevistados. Também nos direciona a uma análise do contexto do aluno em questão. Neste caso, pré-adolescentes e adolescentes. Foi perguntado ao aluno a série que estuda, idade e sexo.

Nossos dados apontam para a pré-adolescência e adolescência. De acordo com as fases do desenvolvimento humano, a pré-adolescência é entendida como uma fase intermediaria entre a infância e a adolescência. Nesta fase define-se socialmente, o que leva a uma construção de valores que precisam ser amplamente discutidos entre a família, escola e o ambiente culturalsocial em questão (BOGOYAVLENSKY e MENCHINSKAYA, 1991).

A relação que o pré-adolescente estabelece com o outro auxilia no processo de inquirição e dúvida em relação ao mundo criado por ele. Nesse momento torna-se fundamental a construção e estabelecimento de regras que podem ser flexíveis possibilitando sua adaptação. Ele pode enfrentá-las, contrariá-las, levando a uma ressignificação das mesmas, elaborando as suas próprias regras. A motivação é a competitividade na busca pela afirmação diante do grupo ao qual pertence (PIKUNAS, 1979).

A adolescência é uma fase da vida caracterizada pela intensidade das emoções e da construção e reconstrução da identidade. $O$ adolescente mergulha no questionamento de si mesmo 


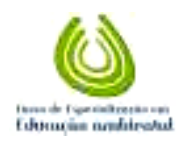

\section{HILLIG et al, vol.(4), n4, p. 647-659, 2011. \\ Monografias Ambientais (e-ISSN: 2236-1308)}

REMOA

com características singulares, confrontando-se com a família, o grupo, a cultura e a sociedade, tentando descobrir-se único, ou seja, parte significante de um todo construído historicamente. Nesse sentido, precisa estabelecer seus próprios valores ao ver o mundo sob sua ótica.

Quanto ao agrupamento por idades nossos dados revelam que poucos alunos estão em distorção série-idade considerando o avanço regular de escolas de ensino regular, como podemos confirmar a seguir:

Tabela 2. Análise geral das idades e séries freqüentadas pelos estudantes.

\begin{tabular}{clll}
\hline Idade & $5 \underline{a}$ & $6 \underline{a}$ & $7 \underline{a}$ \\
\hline 10 & 7 & 0 & 0 \\
\hline 11 & 10 & 8 & 0 \\
\hline 12 & 4 & 11 & 6 \\
\hline 13 & 3 & 10 & 10 \\
\hline 14 & 1 & 2 & 1 \\
\hline 15 & 0 & 0 & 1 \\
\hline Não & & & \\
rocnnndaw & $n$ & $n$ & 1
\end{tabular}

Em relação à divisão por sexo nossos dados revelam a seguinte configuração.

Tabela 1. Identificação dos sexos dos alunos estudados

\begin{tabular}{llll}
\hline Sexo & $5 \underline{a}$ & $6 \underline{a}$ & $7 \underline{a}$ \\
\hline Masculino & 16 & 10 & 9 \\
\hline Feminino & 9 & 20 & 9 \\
\hline $\begin{array}{l}\text { Não } \\
\text { Rocnondou }\end{array}$ & 0 & 1 & 1
\end{tabular}

Buscamos aqui ressaltar a importância de construir cada vez mais uma autonomia cidadã buscando a transformação da realidade, por meio de ações que envolvem tanto a escola com trabalhos de intervenção interdisciplinares e transversais com a comunidade escolar numa constante busca do conhecimento na interface com uma rede de atores sociais.

O trabalho interdisciplinar e transversal revela que ao observarmos as especificidades do fazer pedagógico inevitavelmente perceberemos as engrenagens que fazem parte de um "mecanismo" global, ou seja, professores, coordenadores, gestores, acadêmicos e principalmente a família devem entrar em sintonia em prol do bem estar da educação de nosso país e o fortalecimento da cidadania.

Com a intenção de expandir na sala de aula seus conhecimentos e levar da palestra informações acerca do tema transversal que possam somar em suas atitudes educacionais cidadãs, buscouse o compartilhamento de atividades educacionais ambientais e o compromisso com a melhora nas atitudes ambientais sociais.

Para efeitos práticos e de espaço tabelamos as questões relacionadas basicamente às categorias que surgiram no decorrer da analise. 
HILLIG et al, vol.(4), n4, p. 647-659, 2011.

REMOA

\section{Monografias Ambientais (e-ISSN: 2236-1308)}

Quadro 1. Análise geral das respostas dadas pelos alunos de todas as séries ${ }^{1}$.

\begin{tabular}{|l|c|l|}
\hline Pergunta & Categoria & Exemplos de resposta \\
\hline $\begin{array}{l}\text { O que você } \\
\text { entende por } \\
\text { Educação }\end{array}$ & $\begin{array}{l}\text { Relacionado } \\
\text { com a Escola }\end{array}$ & $\begin{array}{l}\text { "Eessoas a } \\
\text { conservar o planeta". }\end{array}$ \\
\hline
\end{tabular}

6 Por questão de espaço selecionamos algumas respostas relevantes.

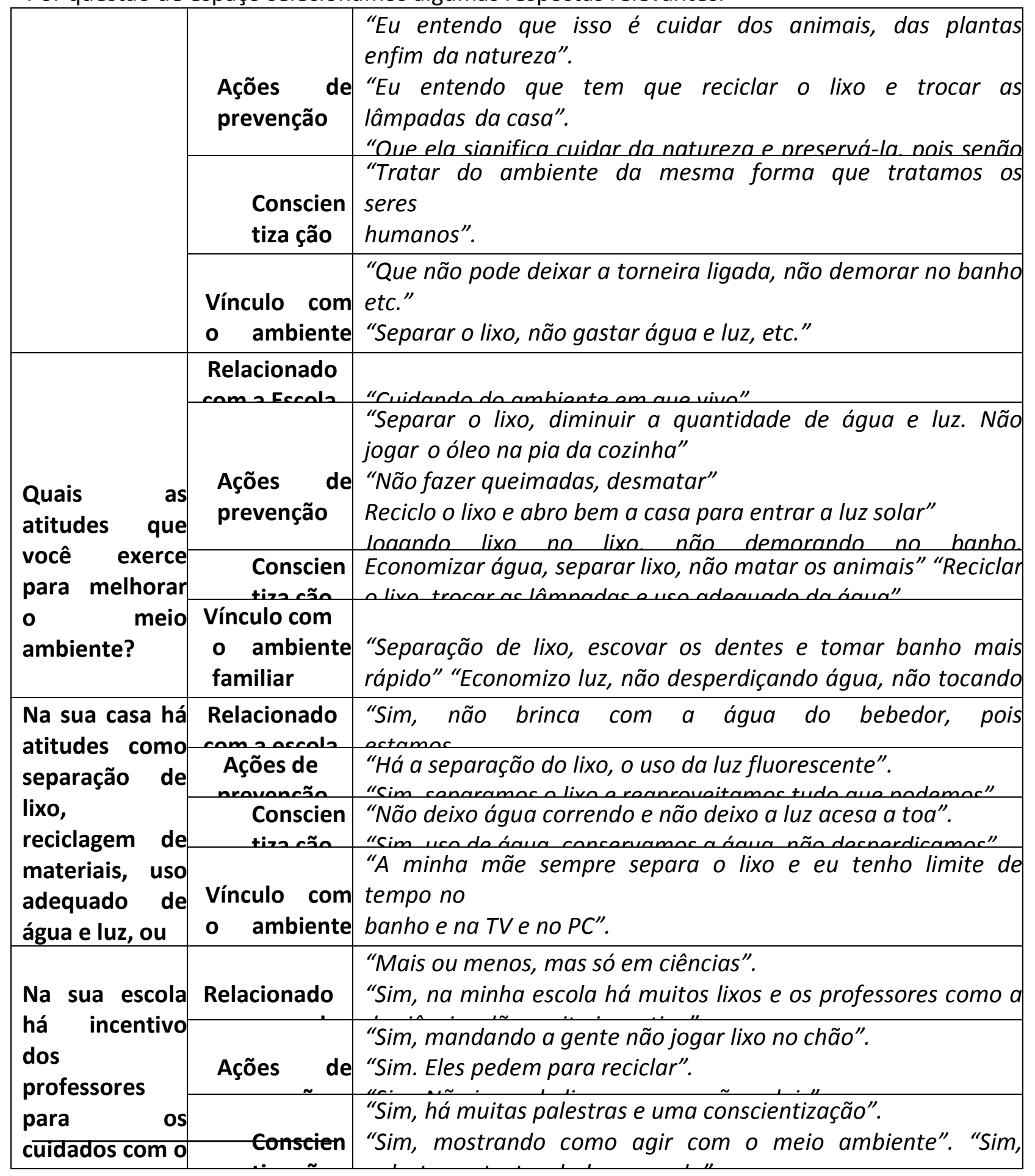


HILLIG et al, vol.(4), n4, p. 647-659, 2011.

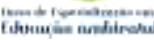
Monografias Ambientais (e-ISSN: 2236-1308)

REMOA

\begin{tabular}{|c|c|c|}
\hline $\begin{array}{l}\text { meio } \\
\text { ambiente? }\end{array}$ & $\begin{array}{l}\text { Vínculo com } \\
\text { o ambiente }\end{array}$ & $\begin{array}{l}\text { "Sim. Não jogar o lixo no chão, trabalhos para incentivar não } \\
\text { só as }\end{array}$ \\
\hline $\begin{array}{l}\text { Quais locais } \\
\text { você percebeu }\end{array}$ & $\begin{array}{l}\text { Relacionado } \\
\text { cam s accols }\end{array}$ & $\begin{array}{l}\text { "Em algumas escolas. Os alunos e professores começam a } \\
\text { limnar } \\
\text { "As secas no RS os pólos derretendo". } \\
\text { "Nos pólos, na s florestas a seca aqui no RS por causa }\end{array}$ \\
\hline $\begin{array}{l}\text { que houveram } \\
\text { alteração }\end{array}$ & Conscien & $\begin{array}{l}\text { "Todo o mundo. Estão poluindo e gastando água e luz". } \\
\text { "Amazônia e Pantanal, pólo norte, os seres humanos }\end{array}$ \\
\hline $\begin{array}{l}\text { ecológica? Por } \\
\text { quê? }\end{array}$ & $\begin{array}{l}\text { Vínculo com } \\
\text { o ambiente }\end{array}$ & "Na minha \\
\hline
\end{tabular}

\section{Relacionado com a Educação Ambiental, ou seja, com o ambiente escolar}

A primeira pergunta do segundo bloco foi direta instigando o aluno a responder sobre a sua concepção de educação ambiental. "O que você entende por Educação Ambiental?".

Basicamente podemos concluir que todos os alunos relacionaram a Educação Ambiental entre ser humano e natureza. Em sua totalidade, os alunos manifestaram suas respostas em torno das respostas listadas acima, colocando, sempre, uma preocupação em ressaltar que a Educação Ambiental é responsabilidade de todos. Enfatizamos também o forte componente "contexto escolar" levando o aluno às respostas. Como podemos perceber em afirmações como esta:

"Eu entendo que a educação do ambiente que ensina as pessoas a conservar o planeta".

"Eu entendo que educação ambiental ensina para nós o que é melhor para fazer no ambiente".

Para a segunda pergunta "Quais as atitudes que você exerce para melhorar o meio ambiente?", temos respostas que levam a esta categoria tais como:

"Não jogo papel de bala na rua". "Cuidando do ambiente em que vivo".

Estas respostas denotam a relação entre o ato de jogar papel ou lixo com a educação recebida no espaço escolar.

Nesta mesma questão em termos quantitativos, onde os alunos são questionados sobre suas atitudes em relação ao meio ambiente, suas respostas foram satisfatórias, seguidas ainda de justificativas sobre suas ações. Um montante de $96 \%$ dos alunos tem em desenvolvimento atitudes ecológicas benéficas ao meio ambiente. Nesta questão somente dois alunos, ou seja, 3\% dos entrevistados optaram por deixar a resposta em branco e um (aluno), $1 \%$ do total da turma não desenvolve nenhuma atividade benéfica ao meio ambiente.

Retomamos neste momento o terceiro desafio da Política Nacional de Educação Ambiental que preconiza não só a necessidade de um compromisso com a transformação social, mas também, a "vivência efetiva de ações transformadoras, concretamente" (SAITO, 2002).

Em análise a questão quatro, relacionada à Educação Ambiental na escola, 2\% dos entrevistados acreditam que o assunto é desenvolvido na escola somente "Às Vezes", 1\% manifestou que "Mais ou Menos", ou seja, a escola poderia trabalhar um pouco mais sobre o tem Educação Ambiental, 9\% dos alunos foram enfáticos na resposta "Não", justificando que os professores ainda deixam a desejar no assunto. A justificativa para tantos "Não" foi a permanência da luz ligada na sala dos professores durante um período em os mesmos não se encontram no local, e, $87 \%$ acreditam que o assunto é bem trabalhado na escola.

"Sim, há muitas palestras e uma conscientização". "Sim, mostrando como agir com o meio ambiente". 


\section{Monografias Ambientais (e-ISSN: 2236-1308)}

REMOA

"Sim, palestras e textos dados em aula".

Gráfico 1. Análise referente à questão 4, envolvendo as atividades sobre Educação Ambiental na escola.

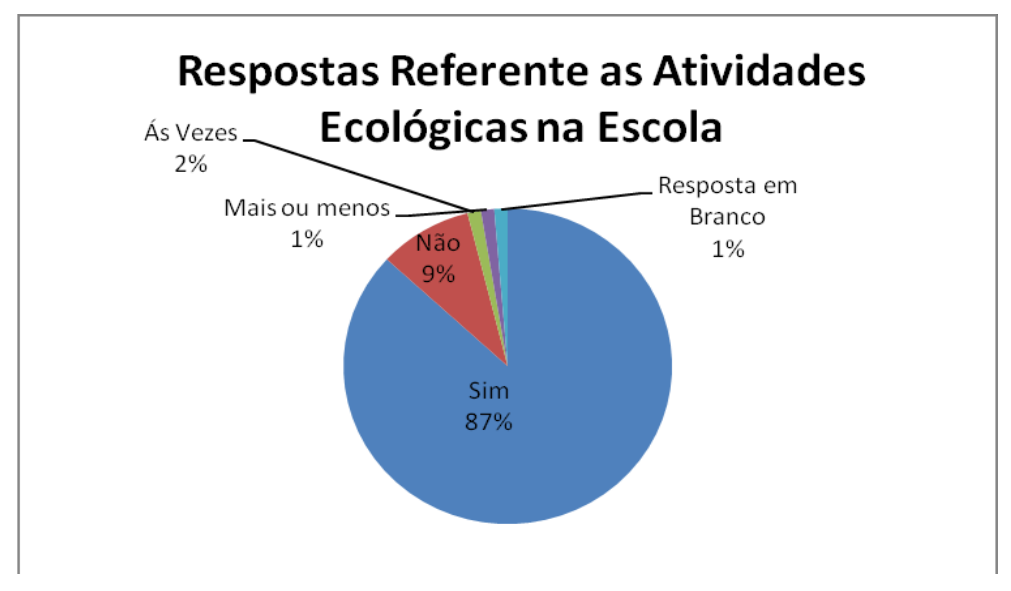

Desta forma podemos perceber que, apesar de haver trabalhos relacionados à EA nas escolas a questão da transversalidade preconizada nos Parâmetros Curriculares Nacionais Temas Transversais (PCN), ainda merecem uma maior atenção. O que os alunos colocam gira em torno de ações específicas e pontuais relacionadas ao tema.

\section{Ações de prevenção}

As ações de prevenção que aparecem nas respostas dos questionados nos levam a questões levantadas na escola ao trabalhar o tema. Na escola o professor possibilita uma ênfase maior para a comunidade em que ela está inserida, tornando-se muitas vezes o único vinculo do aluno com a educação ambiental. A escola transforma-se na origem de um conjunto de ações relacionados com a comunidade escolar.

Enfatizamos também nesta oportunidade a responsabilidade pessoal de cada individuo na conservação do meio em que vive. Se o aluno não percebe a sua função como ser inserido no contexto, não vai haver ação significativa a favor do meio ambiente, ou seja, não adiantam ações nacionais ou globais, se o próprio individuo não perceber o seu papel como agente transformador. Os alunos devem aprender a "pensar globalmente enquanto agem localmente".

Percebemos essas intenções de prevenção ambiental, entre outras, em respostas como estas:

"Separar o lixo, diminuir a quantidade de água e luz. Não jogar o óleo na pia da cozinha".

"Não fazer queimadas, desmatar".

"Reciclo o lixo e abro bem a casa para entrar a luz solar".

"Jogando lixo no lixo, não demorando no banho, economizando água".

Estas ações levam diretamente a terceira categoria elencada no conjunto de respostas dos alunos que trataremos a seguir. 


\section{Conscientização}

Os dados apontam para a importância da inserção e conscientização da Educação Ambiental no ambiente escolar. Como podemos perceber pelas respostas apresentadas. As aulas de Ciências são citadas como responsáveis pelo desenvolvimento do tema na escola. Corrobora com nossos dados Koff (1995) quando a mesma enfatiza que:

A escola e, muito especialmente, o ensino de Ciências têm um papel de extrema importância na conscientização sobre a necessidade de se ser educado ambientalmente. Parece estranho enfatizar-se educação ambiental, dando, talvez, a idéia errônea de que ela está dissociada da educação em que estão implícitas todas as dimensões que tornam o Homo sapiens justamente um ser humano (KOFF, 1995, p. 27).

Nessa perspectiva torna-se fundamental que as atividades relacionadas à Educação Ambiental estabeleçam interconexões entre o ambiente natural e sociocultural em questão.

Nossos dados apontam que a maioria dos alunos apresenta atividades ecologicamente corretas em suas residências e tem a consciência necessária para a melhoria do ambiente.

Tanto na escola como em suas casas os alunos são instruídos e incentivados a preservar o meio ambiente.

Desta forma podemos perceber que, apesar de haver trabalhos relacionados à EA nas escolas a questão da transversalidade que inspira o trabalho em todos os componentes curriculares no sentido da busca pela formação cidadã ainda merece um trabalho mais efetivo.

Buscamos aqui ressaltar a importância de construir cada vez mais uma autonomia cidadã buscando a transformação da realidade, por meio de ações que envolvem tanto a escola com trabalhos de intervenção interdisciplinares, como a comunidade escolar numa constante busca do conhecimento na interface com uma rede de atores sociais.

O trabalho de interdisciplinaridade revela que ao observarmos as especificidades do fazer pedagógico inevitavelmente perceberemos as engrenagens que fazem parte de um "mecanismo" global. Ou seja, professores, coordenadores, gestores, acadêmicos e principalmente a família devem entrar em sintonia em prol do bem estar da educação de nosso país e o fortalecimento da cidadania.

\section{Vínculo com o ambiente familiar}

As ações relacionadas nas respostas apontam para questões cotidianas desenvolvidas no ambiente escolar e doméstico. Para tanto usamos Currie (2006) que reforça dizendo:

Se tanto tu como a tua família podem fazer tantas coisas para resolver problemas como à chuva ácida e o efeito estufa, imagina o poder que terão centenas de consumidores ecológicos, se trabalharem em conjunto na escola. E, se todas as escolas fizessem o mesmo, os resultados seriam excelentes. (ELKINGTON e HAILES 1991, p. 60 apud CURRIE, 2006, p. 55).

Desta forma fica nítida a importância do trabalho escolar na formação do cidadão inserido no contexto social onde a escola está, ou seja, a comunidade escolar. A evidência do trabalho 


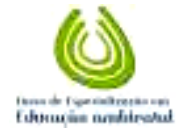

REMOA

\section{HILLIG et al, vol.(4), n4, p. 647-659, 2011. \\ Monografias Ambientais (e-ISSN: 2236-1308)}

escolar se dá pela necessidade da formação de cidadãos responsáveis, que "como empreendedores, venham agir de forma responsável e com sensibilidade" (PCN-Tema Transversal Meio Ambiente e Saúde, 1997, p. 25).

Respostas, como estas reforçam a importância do ambiente familiar na formação do cidadão, vinculada com a escola e comunidade.

"Separação de lixo, escovar os dentes e tomar banho mais rápido".

"Economizo luz, não desperdiçando água, não tocando lixo nas ruas e também separando lixos (seco e orgânico)".

A interface família-escola no contexto ambiental é reforçada pelas ações domésticas mais com uns, e que são fundamentais no contexto geral. Além disso, o PCN traz considerações enfatizando que:

Há outros componentes que vem se juntar à escola nessa tarefa: a sociedade é responsável pelo processo como um todo, mas os padrões de comportamento da família e as informações veiculadas na mídia exercem especial influencia sobre as crianças (PCN, 1997, p. 29).

Na quinta questão os alunos tiveram a oportunidade de expor os locais que verificaram alterações ambientais ao longo de alguns anos. Em 1\% das respostas os alunos colocaram que não sabem onde houve alterações ambientais no mundo, outro $1 \%$ não verificou em parte alguma tais alterações, enquanto $11 \%$ optaram por deixar a resposta em branco e $87 \%$ dos alunos responderam e exemplificaram as alterações ambientais que verificaram até então.

Gráfico 2. Verificação dos alunos em relação às alterações ambientais mundiais.

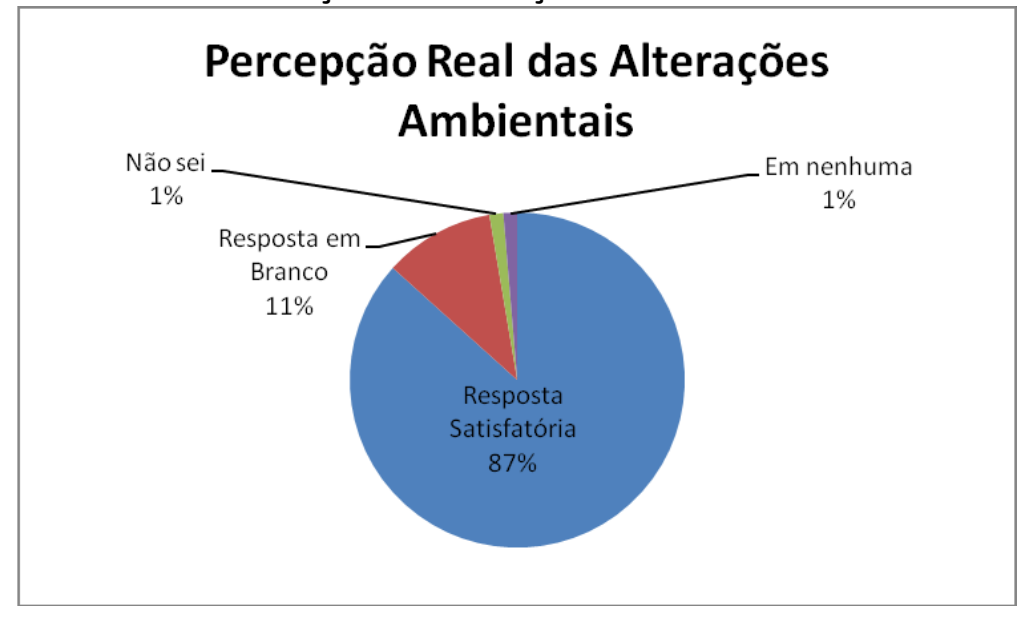

As respostas abaixo trazem a percepção dos alunos acerca das transformações ambientais ocorridas nos últimos anos.

"As secas no RS os pólos derretendo".

"Nos pólos, nas florestas a seca aqui no RS por causa do aquecimento global causado pelo homem". "Todo o mundo. Estão poluindo e gastando água e luz".

"Amazônia e Pantanal, pólo norte, os seres humanos agridem o meio ambiente". "Na minha casa porque eu colaborei bastante e houveram alteração".

O PCN enfatiza a importância de se trabalhar alguns termos, tais como: proteção, preservação, conservação, recuperação, degradação. Para tanto são necessárias ações que desmistifiquem a questão ambiental. A mesma não deve ficar somente a preservação de ambientes, mas, sim na consideração de que: 


\section{HILLIG et al, vol.(4), n4, p. 647-659, 2011. Monografias Ambientais (e-ISSN: 2236-1308)}

REMOA

[...] como a realidade funciona de um modo sistêmico em que todos os fatores interagem, o ambiente humano deve ser compreendido com todos os seus inúmeros problemas. Tratar a questão ambiental, portanto, abrange toda a complexidade da ação humana: se quanto às disciplinas do conhecimento ela é um tema transversal, interdisciplinar, nos setores de atuação da esfera pública ela só se consolida numa atuação do sistema como um todo, sendo afetada e afetando todos os setores: educação, saúde, saneamento, transportes, obras, alimentação, agricultura, etc. (PCN, 1997, p. 44).

Em análise mais detalhada o trabalho trouxe um resultado satisfatório em relação aos alunos pesquisados. Em sua maioria as respostas foram acordando com as atitudes ambientais esperadas. Poucas respostas foram negativas e/ou em branco alcançando, assim, o objetivo e a satisfação em saber que as escolas cumprem em parte seu papel de formação educacional englobando algumas áreas e os mais diversificados assuntos.

\section{CONSIDERAÇÕES FINAIS}

Com o desenvolvimento da atividade propostas na escola, os relatos dos alunos envolveram a Educação Ambiental com o meio ambiente, seus cuidados e a ação humana.

A proposta inicial foi a de levar a comunidade escolar os conceitos voltados a Educação Ambiental e verificar o que estes estudantes têm como conceitos já formados sobre o tema. Para tanto, as palestras trouxeram e agregaram conhecimentos aos conceitos pré-estabelecidos dos mesmos sobre o assunto.

Neste contexto as respostas permitem apontar que os alunos têm informações na escola e em suas residências sobre a ação ambiental mundial. Os mesmos ressaltam a importância das ações com o meio onde nos inserimos, e, visualizam atitudes que possam trazer resultados ainda melhor em contribuição ao ecossistema em que nos envolvemos diretamente.

Os manifestos relatados na pesquisa em benefício ao meio ambiente já vinculam uma ação satisfatória desenvolvida pelos membros de suas residências, bem como as atitudes expostas na escola relacionadas ao tema. Com leves críticas os alunos ainda julgam uma boa iniciativa realizada pela escola sobre o assunto. Os mesmos ainda ressaltam a necessidade de melhoras em suas atitudes no ambiente escolar, em suas residências, entretanto, buscam reparar os danos ao meio ambiente da melhor forma.

Em suas próprias análises, a crítica voltada às atitudes que causam danos ao meio ambiente já é ressaltada. Com citações e explicações, os alunos criticam situações que visualizam na própria escola. Em contrapartida, analisam a satisfação em poder trabalhar os temas voltados a Educação Ambiental na disciplina de Ciências, principalmente.

Em análise do trabalho verifica-se na escola a interdisciplinaridade, e a presença da transversalidade, pois as palestras envolveram as disciplinas de Ciências, Geografia e Português, permitindo que os educadores pudessem trabalhar interdisciplinarmente.

Os pesquisados já possuem uma visualização crítica sobre as ações realizadas por si e por seus colegas no momento em que se encontram no ambiente escolar, e com tal ação, uma melhora significativa envolvendo a Educação Ambiental poderá acontecer.

Finalmente, os resultados das palestras realizadas na escola foram valiosos, pois acrescentaram aos alunos os conceitos e conhecimentos já adquiridos pelos mesmos no ambiente escolar e 


\section{HILLIG et al, vol.(4), n4, p. 647-659, 2011. Monografias Ambientais (e-ISSN: 2236-1308)}

REMOA

em suas residências.

\section{REFERÊNCIAS BIBLIOGRÁFICAS}

ANTUNES, P. B.. Direito Ambiental. 4ed. Rio de Janeiro: Lúmen Júris, 2000.

BECK, U. La sociedade del riesgo: hacia uma nueva modernidad. Barcelona: Paidós, 2006.

BRASIL. Parâmetros Curriculares Nacionais: Temas Transversais: Meio ambiente. Secretaria de Educação Fundamental - MEC/SEF, 1997.

BRASIL. Lei 9795/99. Dispõe sobre a educação ambiental, institui a Política Nacional de Educação Ambiental. Brasília: DF. 1999.

BORGES, R. M.R; BASSO, N. R. S; FILHO, J. B. R. Avaliação e Interatividade na Educação Básica em Ciências e Matemática. 2008. Porto Alegre. EDIPUCRS. 184p.

BORGES, R. M.R; BASSO, N. R. S; FILHO, J. B. R. Propostas Interativas na Educação Científica e Tecnológica. 2008. Porto Alegre. EDIPUCRS. 176p.

DEMO, P. Educar pela Pesquisa. 2007. Campinas. Autores Associados. 130p.

CURRIE, K. Meio ambiente: Interdisciplinaridade na prática. Campinas. SP: Papirus, 1998.

FERNANDES, I. S.. Metodologia para trabalhos científicos. Goiânia, GO: Impresso Digital, 2010.

FRIEDRICH, M. O Programa Nacional de Inclusão de Jovens - PROJOVEM: Uma Análise Entre o Proposto e o Vivido em Goiânia. Dissertação de Mestrado, UFG, 2009, disponível em http://www.sistemasconsultoria.com.br/mecm/Diss_MarciaFriedrich.pdf.

GADOTTI, M. Escola Cidadã, Cidade Educadora: Projetos e práticas em processo. V Fórum de Educação CEAP. Salvador, 23 de outubro de 2003.

GOOGLE MAPS. Localização de endereço. Disponível em http://maps.google.com.br/maps?hl=pt- BR\&tab=wl. Acesso em 27/05/2009.

GRÜN, M. Ética e Educação Ambiental: a conexão necessária. Campinas: Papirus, 1996.

JACOBI, P. Educação ambiental, cidadania e sustentabilidade. In: Cadernos de Pesquisa, no118. São Paulo: Fundação Carlos Chagas, 2003. Pp 189-205.

KOFF, E. D. A Questão Ambiental e o estudo de Ciências: algumas atividades. Goiânia, GO: Editora UFG, 1995.

LUDKE, Menga, ANDRÉ, Marli E. D. A.. Pesquisa em Educação: abordagens qualitativas. São Paulo. EPU: 1986.

LUNDGREN, U. Teoria del curriculum y escolarización. Madri: Morata, 1992.

MARCONI, M. A.; LAKATOS, E. M. Fundamentos de Metodologia Científica. São Paulo: Editora Atlas, 2003.

PIKUNAS, J. Desenvolvimento humano. São Paulo: Hill do Brasil, 1979.

REMEA. Implementação da Educação Ambiental em Escolas: uma reflexão. Disponivel em http://www.remea.furg.br/mea/remea/vol4c/daniel.htm. acesso em 03/06/2009. 


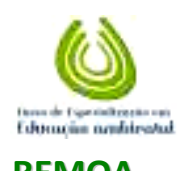

\section{HILLIG et al, vol.(4), n4, p. 647-659, 2011. \\ Monografias Ambientais (e-ISSN: 2236-1308)}

\section{REMOA}

SAITO. C. H. Política Nacional de Educação Ambiental: Desafios Contemporâneos. In:

RUSCHEINSKY, A. Educação Ambiental. Abordagens Múltiplas. Porto Alegre, Artmed, 2002.

RUSCHEINSKY, A. Educação Ambiental. Abordagens Múltiplas. Porto Alegre, Artmed, 2002.

SAGAN, C. B. e B.. Reflexões sobre a vida e morte na virada do milênio. Cia. das Letras, 1998, São Paulo.

STERLING, S. "Education in Change". In: HUCKLE, J. and STERLING, S. Education for sustainability. London: Earthscan Publications Ltd, 1996. Pp. 18- 39.

UNESCO. Declaração de Hamburgo sobre a Educação de Adultos e Plano de Ação para o Futuro. In: Conferencia Internacional Sobre a educação de Adultos, 1997, Hamburgo, Alemanha, 14-18 jul. 1997. VYGOTSKY, L. A formação social da mente. Livraria Mar 